\title{
Qualidade microbiológica do Brycon microleps (piraputanga) de cativeiro e capturado no rio Cuiabá-MT
}

\section{Microbiologycal quality of Brycon microleps (piraputanga) from farm fish and from the Cuiabá river-MT}

\author{
Cássia Aldrin de Mello, ${ }^{*}$ Emiko Shinozaki Mendes, ${ }^{* *}$ Edivaldo Sampaio de Almeida Filho, ${ }^{*}$ Marilu Lanzarin, ${ }^{*}$ \\ Simone Francisca de Lira, ${ }^{* * *}$ Márcia Maria de Souza Americano ${ }^{* * *}$
}

\begin{abstract}
Resumo
A bacia do rio Cuiabá, no estado de Mato Grosso, é uma das principais receptoras de esgotos domésticos e industriais, e por isto, os peixes capturados nesta região podem estar contaminados, sendo a criação de peixes em cativeiro uma alternativa para a obtenção de peixes de melhor qualidade microbiológica. Exemplares de Brycon microleps (piraputanga) oriundos do rio Cuiabá e também de cultivo em Mato Grosso, foram analisados quanto às bactérias heterotróficas aeróbias mesófilas, coliformes termotolerantes, Aeromonas spp. e Salmonella spp., nos meses de chuva e seca. Dos exemplares foram utilizados fígados, e para a comparação dos dados utilizou-se a correlação de Spearman e o teste de Kolmogorov-Smirnov. Verificou-se o efeito da sazonalidade (mês de coleta) sobre a contagem de bactérias heterotróficas aeróbias mesófilas, coliformes termotolerantes e Aeromonas spp., tanto em peixes capturados no rio como nos cultivados. As maiores contagens foram observadas no final do período seco e no início do período chuvoso, ou seja, nos meses mais quentes do ano, entre agosto e março. Foram isoladas A. hydrophila, A. caviae, A. sobria, Salmonella spp., Escherichia coli, Pantoea agglomerans, Serratia ficaria, Serratia rubidea, Edwardsiella tarda, Klebsiella oxytoca e Proteus vulgaris. Verificou-se que a probabilidade de ocorrência da contaminação por mesófilos em peixes capturados no rio é a mesma nos obtidos em cultivo.
\end{abstract}

Palavras-chave: peixe, Brycon microleps, contaminação, micro-organismos.

\begin{abstract}
Cuiabá river basin, in Mato Grosso State is one of means river receivers of domestic sewage and industries effluents, for them, fishes captured can become contaminated, being rasing of fishes capitivity a viable alternative to provide better quality fish. Specimes of Brycon microleps (piraputanga) captured both from the captivity and from the river in MT were studied microbiologically about the mesophiles, total and termtolerants coliforms, Aeromonas and Salmonella, on rain season, and dry season. About specimes were collected liver and the compared of values were used the test of correlation of Spearman and the Kolmogorov-Smirnov test. It was verified the sazonalidad effect (month of collection) over the counting of aerobic heterothrophic mesophile, termtolerants coliforms and Aeromonas, at both fish obtained from captivity and river. Higer contamination were observed in finish of dry season and all dry season, then, at most months hots, between August and March. The isolates were A. hydrophila, A. caviae, A. sobria, Salmonella spp., Escherichia coli, Pantoea agglomerans, Serratia ficaria, Serratia rubidea, Edwardsiella tarda, Klebsiella oxytoca e Proteus vulgaris. It was verified that the probability of contamination by mesophiles occurrence in river collected fish is the same as captivity ones.
\end{abstract}

Keywords: fish, Brycon microleps, contamination and microorganisms.

\section{Introdução}

A bacia do rio Cuiabá é uma das mais importantes do estado de Mato Grosso e abrange uma extensa área, onde estão inseridos os municípios de Cuiabá e Várzea Grande. Esses núcles urbanos são considerados os principais responsáveis pela poluição orgânica e microbiológica do rio Cuiabá, causando a contaminação da ictiofauna local (FEMA, 2003).
A contaminação excessiva do meio ambiente de Mato Grosso tem sido provocada pelo intenso crescimento de indústrias agrícolas, com eliminação de resíduos poluidores nos rios, como o rio Cuiabá, elevando a carga microbiana destes. Apenas $6 \%$ do esgoto doméstico de Cuiabá são tratados e o restante, despejado nos pequenos córregos espalhados por toda a cidade, que desaguam no rio Cuiabá, contaminando-

\footnotetext{
* Universidade Federal de Mato Grosso, Dpto. de Ciências Básicas e Produção Animal - Av. Fernando Corrêa da Costa, s/n - Coxipó - Cidade Universitária, Cuiabá/MT. CEP 78060-900.

** Universidade Federal Rural de Pernambuco, Dpto. de Medicina Veterinária - Rua Dom Manuel de Medeiro s/n, Dois Irmãos, Recife/PE. CEP 52171-900.

*** Médica-veterinária autônoma, Rua 41, 55 5ํㅗㄹ Etapa - Rio Doce, Olinda/PE, CEP 15553-010.

**** Universidade de Cuiabá, Faculdade de Farmácia - Av. Beira Rio, 3100, Jd. Paulista, Cuiabá/MT. CEP 78000-000
} 
o e causando doenças à população, além de reduzir os estoques de pescados (Piaia, 1999).

Uma alternativa viável para suprir a carência dos recursos da pesca decorrente da intensa degradação dos rios é a piscicultura, sendo que o estado possui condições ideais para a criação de peixes em cativeiro, como água em abundância, clima adequado e território extenso e plano.

Em função da expressiva disponibilidade de recursos hídricos do estado, a pesca constitui a segunda maior atividade econômica do Pantanal, o que faz do peixe o símbolo culinário da cultura mato-grossense, sendo a piraputanga (Brycon microleps) um dos principais exemplares de sua fauna aquática e de grande aceitabilidade pelos consumidores (Sillimon, 1994).

Vieira et al. (2000), afirmam que toda a forma de contaminação ambiental acaba por retornar ao homem também de forma agressiva, neste caso, pela ingestão de peixes de baixa qualidade higiênico-sanitária que podem ser nocivos à saúde do consumidor.

Considerando-se que a contaminação multifatorial do rio Cuiabá pode resultar como consequência direta a chegada à mesa do consumidor de peixes contaminados, objetivouse neste trabalho avaliar a qualidade microbiológica de Brycon microleps (piraputanga) capturados no rio Cuiabá e cultivados em piscicultura, nos meses de chuva e seca, através da contagem de bactérias heterotróficas aeróbias mesófilas, Aeromonas spp., coliformes totais e termotolerantes e pesquisa de Salmonella spp., e desta maneira, fornecer subsídios a respeito do monitoramento do ambiente aquático de tamanho interesse e importância para a potencialização das atividades econômicas regional.

\section{Material e métodos}

Amostras de peixes da espécie Brycon microleps (piraputanga) capturadas no rio Cuiabá e em um viveiro de piscicultura, ambos no município de Várzea Grande, MT, foram mensalmente coletadas, no período de maio de 2006 a abril de 2007, abrangendo o período de chuvas $(\mathrm{CH})$ - novembro a abril e o período de seca (SE) - de maio a outubro, objetivando-se analisar e comparar a qualidade microbiológica dos peixes e estudar o efeito da sazonalidade sobre os microorganismos pesquisados.

Cada amostra foi composta por três a seis peixes, variável de acordo com o tamanho, com a finalidade de se obter uma quantidade suficiente de fígado para a realização das análises. As unidades amostrais foram obtidas pelo macerado de fígado dos peixes, em virtude de ser um órgão hematopoiético e passível de nele se encontrar micro-organismos e ainda, segundo Vieira (2004), pelo fato da musculatura dos peixes ser considerada estéril.

As análises foram realizadas no Laboratório de Inspeção de Carne e Leite (LICAL) do Departamento de Medicina Veterinária da Universidade Federal Rural de Pernambuco (UFRPE), consistindo de contagem de coliformes totais e termotolerantes, pesquisa de Salmonella spp. e contagem de bactérias heterotróficas aeróbias mesófilas, por serem as bactérias indicadoras da qualidade higiênico-sanitárias de peixes. Adicionalmente, foram realizadas contagens e identificação de Aeromonas spp., por serem bactérias normalmente presentes em água, sendo isoladas com frequência em peixes, além de serem agentes etiológicos de enfermidades. Os métodos utilizados foram os da Intrução Normativa 62, do Ministério da Agricultura, Pecuária e Abastecimento (BRASIL, 2003), exceto para contagem e identificação de Aeromonas spp., em que se utilizou o método preconizado por Mores (1994). As avaliações estatísticas foram realizadas através de teste não paramétrico de associação/correlação de Spearman e o teste não paramétrico de Kolmogorov-Smirnov (Zar, 1999), ambos ao nível de $5 \%$ de significância.

\section{Resultados e discussão}

As contagens de bactérias heterotróficas aeróbias mesófilas, durante o período seco (SE), variaram de $0,3 \times 10^{1}$ a $2,7 \times 10^{5}$ UFC/g e $4,8 \times 10^{1}$ a $2,3 \times 10^{5} \mathrm{UFC} / g$ para peixes de viveiro e rio, respectivamente. Durante o período chuvoso $(\mathrm{CH})$, as contagens em peixes de viveiro variaram de $3,6 \times 10^{2}$ a $6,3 \times$ $10^{4} \mathrm{UFC} / \mathrm{g}$ e de $2,3 \times 10^{2}$ a $5,6 \times 10^{5} \mathrm{UFC} / \mathrm{g}$ em peixes de rio.

Os resultados das contagens de bactérias heterotróficas aeróbias mesófilas do total de amostras analisadas nos dois períodos - SE e $\mathrm{CH}$ - estiveram abaixo dos achados por Andrade et al. (2002), que pesquisaram bactérias mesófilas em peixes comercializados no Rio de Janeiro e encontraram variações de $<10^{5}$ a $9,4 \times 10^{8} \mathrm{UFC} / \mathrm{g}$. GonzálesRodrígues et al. (2001) analisaram peixes comercializados em supermercados na Espanha, encontrando contagens máximas de 5,27 x $10^{6} \mathrm{UFC} / \mathrm{g}$. Almeida Filho et al. (2002) verificaram contagens entre $2,0 \times 10^{5}$ a $5,3 \times 10^{5} \mathrm{UFC} / \mathrm{g}$ em todas as amostras de peixes comercializados em Cuiabá.

Cabe ressaltar que os trabalhos supracitados foram realizados em amostras de músculo de peixes coletadas no comércio, logo, submetidas a manipulações diversas. As amostras deste trabalho, além de terem sido coletadas diretamente da produção (rio e viveiro) e acondicionadas com cuidados higiênicos para não mascarar a qualidade do local de captura, constaram de macerado de fígado, pois o músculo, neste caso, supostamente estava estéril. Estes fatos podem ter contribuído para as menores contagens de mesófilos.

Os coliformes totais variaram de $<3$ a $2,4 \times 10^{3} \mathrm{NMP} / \mathrm{g}$ e $<3$ a $2,4 \times 10^{3} \mathrm{NMP} / \mathrm{g}$ em peixes de viveiro e rio, respectivamente, durante o período $\mathrm{SE}$, enquanto no período $\mathrm{CH}$ as contagens foram de $<3$ a 2,4 $\times 10^{2} \mathrm{NMP} / \mathrm{g}$ em peixes de viveiro e de $<3$ a $2,4 \times 10^{3} \mathrm{NMP} / \mathrm{g}$ em peixes de rio. Durante o período de SE, contagem de coliformes termotolerantes com variações de $<3$ a 2,4 x 10 $0^{3} \mathrm{NMP} / \mathrm{g}$ e $<3$ a $1,1 \times 10^{3} \mathrm{NMP} / \mathrm{g}$, para peixes de viveiro e rio, respectivamente. Durante o período $\mathrm{CH}$, as contagens estiveram entre $<3$ a 4,3 x $10 \mathrm{NMP} / \mathrm{g}$ e $<3$ a 2,4 x $10^{3} \mathrm{NMP} / \mathrm{g}$, para peixes de viveiro e rio, respectivamente.

$\mathrm{Na}$ maioria dos trabalhos consultados, foram analisadas amostras obtidas no comércio, portanto, apresentaram contagens maiores que as encontradas neste trabalho (Gonzáles-Rodrígues et al., 2001; Almeida Filho et al., 2002; Andrade et al., 2002); exceção se fez quando os peixes analisados estavam congelados ou resfriados e por isso, apresentaram valores inferiores, devido à ação deletéria do frio sobre os micro-organismos, conforme citado por Vieira (2004). Poucos trabalhos realizados com peixes no comércio apresentaram contagens inferiores aos deste trabalho e podemos atribuir estes resultados à maior contaminação dos pontos de captura das amostras. No entanto, não se 
pode assegurar esta afirmativa, pois não são informadas as contagens daqueles peixes na produção.

Silva et al. (2001), afirmam que os coliformes totais são indicadores de qualidade higiênica, não apontando diretamente o contato do produto com fezes humanas ou de animais. Porém, presume-se o grau de poluição microbiana a que está exposto o alimento em estudo. Indiretamente, estima-se a qualidade das práticas de produção com elevadas concentrações que sinalizam que há necessidade de se rever os procedimentos operacionais para se identificar as causas de contaminação do produto.

A maioria dos pesquisadores concorda que a Escherichia coli é o principal micro-organismo indicador de contaminação fecal do alimento (Silva et al., 2001; Almeida Filho et al., 2002; Vieira, 2004), presumindo-se a possibilidade de germes patogênicos estarem no produto, em razão de suas más condições higiênicas (BRASIL, 2001). Portanto, a ocorrência de $E$. coli nas amostras de peixes de rio $(11,1 \%)$ e viveiro $(33,3 \%)$ pode indicar que, de alguma forma, a água está contaminada com fezes, pois o micro-organismo não faz parte da microbiota natural do peixe (Vieira, 2004).

Almeida Filho et al. (2002) estudando amostras de peixes oriundos do Pantanal mato-grossense e comercializados em supermercados e feiras livres em Cuiabá, encontraram contaminação por coliformes totais em $90,9 \%$ das amostras, com valores variando de $<0,3$ a $1,1 \times 10^{4} \mathrm{NMP} / \mathrm{g}$ em peixes de supermercado e 4,3 x $10^{1}$ a $1,1 \times 10^{6} \mathrm{NMP} / \mathrm{g}$ nos de feiras livres, que são superiores aos verificados nesse trabalho. Apenas uma amostra foi positiva para coliformes termotolerantes, coletada em feira $\left(1,1 \times 10^{3} \mathrm{NMP} / \mathrm{g}\right)$.

Resultados semelhantes foram encontrados por Möllerke et al. (2002) que evidenciaram variações para coliformes totais de $<3,0$ a $1,1 \times 10^{3} \mathrm{NMP} / \mathrm{g}$ e de coliformes termotolerantes de $<3,0$ a $1,1 \times 10^{3} \mathrm{NMP} / \mathrm{g}$, sendo $E$. coli presente em 33,72\% das amostras de peixes oriundos do Lago Guaíba, em Porto Alegre/RS, indicando serem as áreas de captura de qualidade microbiológica semelhante, em se tratando desses micro-organismos.

Agnese et al. (2001) avaliando as condições higiênicosanitárias de 26 amostras de pescado fresco comercializado em Seropédica/RJ, encontraram variações de coliformes totais inferiores, ou seja, 4 a 2,4 $\times 10^{3} \mathrm{NMP} / \mathrm{g}$ e para coliformes termotolerantes de $<3,0$ a 2,3 x $10 \mathrm{NMP} / \mathrm{g}$ e nove amostras positivas para $E$. coli $(34,6 \%)$. Apenas a frequência de $E$. coli foi semelhante nos peixes oriundos de viveiro.

Andrade et al. (2002) analisaram peixes adquiridos em um mercado no município de Campos dos Goytacazer, RJ e encontraram valores superiores ao deste trabalho, com uma variação para coliformes totais de $0,3 \times 10^{3}$ a $3,0 \times 10^{6} \mathrm{UFC} / \mathrm{g}$ para filé de peixe e para peixe inteiro uma variação de $0,5 \times$ $10^{4}$ a $1,5 \times 10^{6} \mathrm{UFC} / \mathrm{g}$ e $66 \%$ das amostras de peixes contaminadas por $E$. coli.

Com relação aos períodos de coleta, as variações encontradas foram muito inferiores aos achados de Liuson (2003), que analisou peixes obtidos diretamente de pesqueiros situados na região metropolitana de São Paulo,

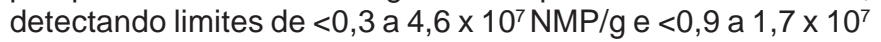
$\mathrm{NMP} / \mathrm{g}$ de coliformes totais, nos períodos $\mathrm{SE}$ e $\mathrm{CH}$, respectivamente.
Pilarski et al. (2004) analisaram microbiologicamente amostras de músculo de carpa comum e água de três viveiros com aporte contínuo de matéria orgânica proveniente de suinocultura e de um viveiro com animais alimentados exclusivamente com ração comercial e com renovação constante de água, situados em Santa Catarina. Detectaram coliformes totais e termotolerantes na maioria das amostras de peixes, com valores oscilando de $<3 \mathrm{NMP} / \mathrm{g}$ a $1,5 \times 10^{2}$ $\mathrm{NMP} / \mathrm{g}$ e $<3 \mathrm{NMP} / \mathrm{g}$ a $1 \times 10 \mathrm{NMP} / \mathrm{g}$, respectivamente. Os autores demonstraram que a qualidade microbiológica dos peixes não foi resultado da situação microbiológica da água dos viveiros e ainda notaram que, no período de chuvas, houve uma tendência para o aumento do número de coliformes totais e termotolerantes nos viveiros consorciados com suinocultura, devido à enxurrada nos viveiros, a qual acarretou maior quantidade de matéria orgânica na água. As espécies de microorganismos da família Enterobacteriaceae isoladas foram Escherichia coli (11,1\%), Pantoea agglomerans $(11,1 \%)$, Serratia ficaria $(11,1 \%)$, Serratia rubidea $(1,11 \%)$, Edwardsiella tarda (22,2\%), Klebsiella oxytoca $(22,2 \%)$ e Proteus vulgaris $(11,1 \%)$ nas amostras de peixes de rio e Pantoea agglomerans (16,6\%), Serratia rubidea (16,6\%), Serratia marcenses (16,6\%), Klebsiella oxytoca $(16,6 \%)$ e Escherichia coli $(33,3 \%)$ nas amostras de peixes de viveiro.

Esposto et al. (2007), ao analisarem a qualidade das tilápias em relação às enterobactérias, bem como a água e a cama de galinha usada como adubo em lagoas de estabilização de uma estação experimental de tratamento de águas residuárias em Petrópolis-RJ, verificaram a presença de 116 cepas de quatro gêneros enteropatógenos, entre as quais os coliformes Edwardsiella tarda (15,5\%) isolada das amostras de músculos, vísceras, guelras e pele. Apesar de ser afirmado por Koneman (2008) que os peixes de água doce são reservatórios de Edwardsiella tarda, estas bactérias são responsabilizadas por muitos casos de gastrenterite e infecções de feridas no humano, além de ser um patogênico para o peixe.

Entre os alimentos incriminados em doenças provocadas por alimentos, o pescado é relevante, uma vez que pode veicular uma gama enorme de micro-organismos patogênicos para o humano, a maior parte resultando da contaminação ambiental, sendo o lançamento de esgotos nas águas de reservatórios, lagos, rios e mares, a causa poluidora mais comumente registrada em muitas regiões do mundo (Alves et al., 2002)

Cardoso et al. (2001), afirmam que as vias de contaminação por coliformes termotolerantes e E. coli, na piscicultura, geralmente ocorre pela água contaminada por fezes recentes, sendo as altas contagens de $E$. coli no pescado indicativo da presença de uma fonte poluidora recente e riscos deste alimento causar doença após sua ingestão.

A ocorrência de $E$. coli em grande número de amostras indica que de alguma forma a água está sendo contaminada com fezes, pois o micro-organismo não faz parte da microbiota natural do peixe (Vieira, 2004). No caso das amostras de rio, a provável causa é a contaminação por esgotos domésticos e industriais (FEMA, 2003), advindos principalmente das cidades de Cuiabá e Várzea Grande (Piaia, 1999) sendo que os peixes foram capturados em uma área de grande descarga destes contaminantes. Nos viveiros, a provável causa pode ter sido a contaminação da água com excrementos de animais como bovinos e ovinos da propriedade, que às vezes 
são colocados para pastar nos arredores dos viveiros, aumentando a contaminação da água por enteropatógenos.

Neste trabalho as contagens de bactérias do gênero Aeromonas variaram de $5,0 \times 10^{2}$ a 8,2 $\times 10^{3} \mathrm{UFC} / \mathrm{g}$, em três amostras de peixe de viveiro, sendo todas no período $\mathrm{CH}$. As amostras de peixe de rio apresentaram de 2,6 $\times 10^{1} \mathrm{UFC} / \mathrm{g}$ a $7,5 \times 10^{2} \mathrm{UFC} / \mathrm{g}$ em três amostras no período SE e de 2,0 $\times 10$ UFC/g em uma amostra no período $\mathrm{CH}$.

Vieira (2004) citou que diferentes fenoespécies de Aeromonas podem predominar em diferentes fontes de água, onde $A$. hydrophila são prevalentes em águas de nascente e pouco poluídas e $A$. sobria em lagos recreacionais e água de rio. Araújo et al. (1991) avaliaram a distribuição de Aeromonas spp. em águas com diferentes níveis de poluição e detectaram predominância de $A$. caviae em águas com maior nível de detritos e poluição fecal. Em águas pouco poluídas (doce e salgada) isolou tanto $A$. caviae quanto $A$. hydrophila, sendo este achado em conformidade com os resultados deste trabalho visto que no rio que apresenta alto nível de poluição fecal, não foi detectada a presença de $A$. caviae.

Araújo et al. (1991) reportaram uma significante correlação entre o conteúdo de matéria orgânica e o número total de Aeromonas spp. na água, ou seja, águas com alto nível de contaminação fecal são passíveis de possuírem grandes contagens de Aeromonas spp., onde obtiveram altas contagens de Aeromonas spp. simultaneamente a altas contagens de coliformes, semelhante ao encontrado neste trabalho em que nos meses em que Aeromonas spp. apresentaram altas contagens os coliformes também apresentaram altas contagens, e nos meses em que não foram isolados Aeromonas ou a contagem de coliformes foi baixa ou nula.

Vieira (2004) verificou que a frequência de isolamento de Aeromonas spp. é mais elevada nos meses de verão, tanto nas zonas temperadas como nas tropicais, ou seja, a variação sazonal depende da temperatura alta, o que foi observado no presente trabalho, em que o isolamento de Aeromonas spp. em amostras de fígado ocorreu nos meses mais quentes do ano, correspondendo ao final do período seco e todo o período chuvoso.

As contagens de Aeromonas spp. de viveiro no presente trabalho estiveram semelhantes aos resultados de Hatha et al. (2005), que isolaram com maior frequência $A$. hydrophila e $A$. sobria em peixes de viveiros na Holanda.

Considerando-se que A. caviae, A. hydrophila e A. sobria são as espécies de maior relevância nos últimos dez anos associadas a patologias intestinais e extraintestinais de humanos e de uma variedade de outros vertebrados e invertertebrados, incluídos peixes, anfíbios e aves, (Singh e Sanyal, 1992), os achados deste trabalho adquirem importância, por serem exatamente as espécies isoladas nas amostras analisadas.

Outro aspecto a ser destacado é o isolamento de Aeromonas hydrophila, porque é a espécie mais associada a infecções em organismos aquáticos, pode causar perdas comerciais onerosas em piscicultura com a síndrome hemorrágica e levar à morte em massa dos peixes (Ranzani-Paiva e Takemoto, 2004).
Ao se utilizar as técnicas estatísticas preconizadas por Mendes et al. (2006) nos resultados das análises microbiológicas em relação à contagem de bactérias heterotróficas aeróbias mesófilas, de coliformes totais (C. totais), de coliformes termotolerantes (C. termot.) e Aeromonas spp., obtiveram-se resultados com elevada variação, os quais estão apresentados na Tabela 1.

Ao se aplicar o teste não paramétrico de associação/ correlação de Spearman (Zar, 1999), ao nível de 5\% de significância, foram obtidos os resultados apresentados na Tabela 2. Foi verificada associação entre o mês de coleta e a contagem de bactérias heterotróficas aeróbias mesófilas, coliformes termotolerantes e Aeromonas spp., tanto em peixes capturados no rio, como nos cultivados, indicativo de que a variável mês interferiu na quantidade destas bactérias. Esta sazonalidade pode ser observada nas quantidades de mesófilos, coliformes termotolerantes e Aeromonas spp. que foram maiores no final do período SE e no início do período $\mathrm{CH}$, ou seja, nos meses mais quentes do ano, entre agosto e março.

Com a aplicação do teste não paramétrico de KolmogorovSmirnov (Zar, 1999), verificou-se que a probabilidade de ocorrência da contaminação por bactérias mesófilas em peixes capturados no rio é a mesma nos obtidos em cultivo $(P \geq 0,05)$.

Baseando-se nos achados de Al-Harbi e Uddin (2005), em que as bactérias mesófilas tiveram suas contagens reduzidas em peixes submetidos ao tratamento pelo frio, é provável que as maiores contagens tenham sido verificadas nos meses mais quentes do ano, em decorrência do caráter de adaptação e multiplicação dos micro-organismos em temperaturas mais altas, apesar de não se ter medido a temperatura da água.

A maior contagem encontrada no período SE (viveiro) provavelmente ocorreu pela redução na diluição da água, com concentração da matéria orgânica (fezes), bem como dos micro-organismos presentes na água, principalmente em consequência da temperatura elevada reinante nesta época do ano. Nas amostras de rio, a maior contagem foi verificada no período $\mathrm{CH}$, o que provavelmente pode ser decorrente do transbordamento de córregos receptores de esgoto na cidade, além da lixiviação da superfície terrestre pelas águas da chuva. Todas as situações citadas aumentam a probabilidade de contaminar os peixes, pois o nível da sua contaminação é diretamente proporcional ao nível de poluição ambiental (El-Shafai et al., 2004).

Os achados de isolamento de Aeromonas spp. são semelhantes aos citados por Vieira (2004), uma vez que a frequência de isolamento de Aeromonas spp. foi mais elevada nos meses mais quentes da região, entre agosto e março, ou seja, a variação sazonal deste micro-organismo foi dependente da temperatura.

Com relação à pesquisa de Salmonella spp. nas amostras de fígado e encéfalo de peixes de rio e peixes de viveiro, ambos apresentaram uma única amostra positiva (8,33\%), no mês de abril $(\mathrm{CH})$. Alguns trabalhos pesquisados indicaram a ocorrência de Salmonella spp. em peixes, tais como: Almeida Filho et al. (2002), que encontraram Salmonella spp. em $16,7 \%$ de amostras de peixes frescos 
Tabela 1: Estatística descritiva das contagens de mesófilos, de coliformes totais e de termotolerantes e de Aeromonas, em piraputangas capturadas no rio Cuiabá e de viveiro

\begin{tabular}{|c|c|c|c|c|}
\hline Estatística & Mesófilos & C. totais ${ }^{(1)}$ & C. termot. ${ }^{(2)}$ & Aeromonas \\
\hline \multicolumn{5}{|l|}{ VIVEIRO } \\
\hline Valor mínimo & $0,3 \times 10$ & $<3$ & $<3$ & $5,0 \times 10^{2}$ \\
\hline Valor máximo & $2,7 \times 10^{5}$ & $? 2,4 \times 10^{3}$ & $? 2,4 \times 10^{3}$ & $8,2 \times 10^{3}$ \\
\hline Mediana & 2 & 11200 & 4 & 0 \\
\hline \multicolumn{5}{|l|}{ RIO } \\
\hline Valor mínimo & $4,8 \times 10$ & $<3$ & $<3$ & $2,0 \times 10$ \\
\hline Valor máximo & $5,6 \times 10^{5}$ & $? 2,4 \times 10^{3}$ & $? 2,4 \times 10^{3}$ & $7,5 \times 10^{2}$ \\
\hline Mediana & 6470 & 5,5 & 1 & 0 \\
\hline
\end{tabular}

(1) C. totais - coliformes totais. (2) C. termot. - coliformes termotolerantes.

Tabela 2: Associação entre a carga bacteriana e o mês de coleta de peixes Brycon microleps de cultivos e capturados no rio Cuiabá-MT

\begin{tabular}{lccc}
\hline \multicolumn{1}{c}{ Variável } & $\begin{array}{c}\text { Valor } \\
\text { calculado }\end{array}$ & $\begin{array}{c}\text { Valor } \\
\text { tabelado }\end{array}$ & $\begin{array}{c}\text { Estatística } \\
\text { comparativa }\end{array}$ \\
\hline Amostras do rio & & & \\
Mês/Mesófilos & 0,9167 & 0,5833 & EDS \\
Mês/Coliformes totais & 0,6667 & 0,68 & NEDS \\
Mês/Coliformes termotolerantes & 0,75 & 0,7239 & EDS \\
Mês/Aeromonas & 0,8333 & 0,7239 & EDS \\
Amostras do viveiro & & & \\
Mês/Mesófilos & 0,9167 & 0,5677 & EDS \\
Mês/Coliformes totais & 0,6667 & 0,6902 & NEDS \\
Mês/Coliformes termotolerantes & 0,6667 & 0,6945 & NEDS \\
Mês/Aeromonas & 0,8333 & 0,7386 & EDS \\
\hline
\end{tabular}

EDS - existe diferença significativa. NEDS - não existe diferença significativa.
Esposto et al. (2007), que analisaram no Rio de Janeiro tilápias criadas e água com aporte de cama de galinha usada como adubo e encontraram Salmonella spp. em $11,1 \%$ das amostras; Morales et al. (2004) que encontraram Salmonella spp. em $2 \%$ de peixes de tanques pesquisados na Costa Rica.

Considerando-se que as salmonelas são amplamente distribuídas na natureza, sendo seu principal reservatório o trato intestinal do humano e animais de sangue quente e de sangue frio (répteis e anfíbios), e que peixes, moluscos e crustáceos se contaminam após a pesca (Vieira, 2004), a ocorrência de Salmonella spp. nas amostras de peixes pode ser atribuída à contaminação da água de captura por material fecal de origem humana ou animal, direta ou indiretamente descarregado neste ambiente. Embora não tenham sido feitas análises de água, muitos autores já comprovaram que a detecção de micro-organismos em vísceras e músculos de peixes pode ser utilizada como indicativo de contaminação ambiental por estes micro-organismos (EIShafai et al., 2004). Desta maneira, a presença de Salmonella spp. no peixe é indicativa de contaminação ambiental por fezes.

Berg e Anderson (1972) relatam que não podem ser descartadas as fezes de pássaros como importantes fontes de contaminação por Salmonella spp. de tanques de piscicultura e comprovaram que $2,1 \%$ de 521 amostras de fezes de aves que visitam criadores no Oregon estavam contaminadas com Salmonella spp., conferindo a estes animais, muitas vezes ignorados, certa relevância no manejo de peixes criados em tanques ao ar livre. em supermercados em Cuiabá; Vieira et al. (2000) que analisaram amostras de tilápias em um frigorífico de uma fazenda de criação de peixes na Paraíba e antes mesmo do processamento encontraram $8,3 \%$ das amostras positivas para Salmonella spp., evidenciando a contaminação dos peixes na captura.

Observa-se que os dados acima variam de $8,3 \%$ a $16,7 \%$; no entanto, semelhante ao ocorrido em relação ao estudo de coliformes termotolerantes, ressalta-se que estes estudos referem-se a amostras coletadas no comércio, enquanto no presente trabalho pesquisou-se o peixe em sua origem. Portanto, desde a captura até as fases de processamento final, muitas fontes podem causar a contaminação do peixe com Salmonella spp., como utensílios e manipuladores (Tessari et al., 2003) e até mesmo o gelo usado para resfriar o peixe (Vieira, 2004), o que torna a comparação dos dados pouco significante.

Alguns autores mostraram a presença de Salmonella spp. em peixes capturados diretamente na produção, como o
Considerando-se que o padrão microbiológico brasileiro (BRASIL, 2001) para Salmonella spp. se refere à ausência do micro-organismo em 25 gramas da amostra, um pequeno percentual das amostras de fígado de peixes de rio (8,33\%) e de viveiro (8,33\%) foram consideradas inaceitáveis para consumo. No entanto, ao compararmos estes dados com trabalhos encontrados na literatura que também analisaram peixes na produção podemos concluir que estiveram acima da maioria dos valores encontrados.

Ainda assim, considerando-se que Salmonella spp. pode ser isolada de águas com diferentes graus de contaminação, e principalmente de águas com despojos de matadouros e efluentes domésticos, esperava-se encontrar um número maior de amostras de peixes positivas que o observado, fundamentalmente nas amostras do rio. No entanto, Vieira (2004) afirma que as cepas poderiam estar numa fase não própria para cultura, ou seja, células viáveis não cultiváveis, sendo necessário o uso de técnicas especiais para sua detecção. 


\section{Conclusões}

$\checkmark$ As contagens de coliformes totais e termotolerantes dos peixes de rio e do viveiro foram iguais e a ocorrência de $E$. coli nos peixes do rio foi indicativo que os dois ambientes estavam contaminados com fezes;

$\checkmark$ Os peixes do rio apresentaram maior contagem de Aeromonas sobria e os do viveiro A. caviae ;

$\checkmark$ A probabilidade da contaminação peixes capturados de rio por bactérias heterotróficas aeróbias mesófilas é a mesma de peixes de viveiro;

$\checkmark$ Existe relação entre o número total de Aeromonas spp. na água e o nível de coliformes, ou seja, quanto maior o

\section{Referências}

AGNESE, A. P. et al. Contagem de bactérias aeróbias heterotróficas mesófilas e enumeração de coliformes totais e fecais em peixes frescos comercializados no município de Seropédica, RJ. Hig. Aliment., v. 15, n. 88, p. 67-70, 2001.

AL-HARBI, A. H. e UDDIN, M. N. Microbiological quality changes in the intestine of hybrid tilapia (Orechromis niloticus $x$ Orechromis. Aureus) in fresh and frozen storage condition. Let. Appl. Microbiol., v. 40 , p. $486-490,2005$.

ALMEIDA FILHO et al. Características microbiológicas de pintado (Pseudoplatystoma fasciatum) comercializado em supermercados e feira livre no município de Cuiabá, MT. Hig. Aliment., v. 16, n. 99, p. 84-88, 2002.

ALVES, C. L. et al. Comercialização de pescado no Distrito federal: avalização das condições. Hig. Aliment., v. 16, n. 102/103, p. 41-49, 2002.

ANDRADE, F. S. V et al. Avaliação sensorial e microbiológica do Peruá (Balistes caprixcus) capturado na região norte fluminense e comercializado no mercado de Campos dos Goytacazes, RJ. Hig. Aliment., v. 16, n. 99, 2002.

ARAÚJO, R. M.; ARRIBAS, R. M.; PARES, R. Distribuition of Aeromonas species in waters with different levels of pollutions. J. Appl. Bacteriol., v. 71, n. 2, p. 182-186, 1991.

BERG, R. W.; ANDERSON, A. W. Salmonella and Edwardsiella tarda in gull feces: a source of contamination in fish processing plants. Appl. Microbiol., v. 24, n. 3, p. 501-503, 1972.

BRASIL. MINISTÉRIO DA SAÚDE. Resolução RDC n 12 de 2 de janeiro de 2001. Regulamento Técnico sobre Padrões Microbiológicos para Alimentos.

CARDOSO, A. L. P. et al. A técnica de membrana filtrante aplicada no estudo bacteriológico da água de rede de abastecimento utilizada pela população de Descalvado, SP. Hig. Aliment., v. 15, n. 82, p. 3338, 2001.

EL-SHAFAI, S. A. et al. Microbial quality of tilapia reared in fecalcontaminated ponds. Environ. Res., v. 95, n. 2, p. 231-238, 2004.

ESPOSTO, E. M. et al. Enteropatógenos bacterianos em peixes criados em uma estação de reciclagem de nutrientes e no ecossistema relacionado. Pesq. Vet. Bras., v. 27, n. 4, p. 144-148, 2007.

FEMA. Implementação de práticas de gerenciamento em bacias hidrográficas de Mato Grosso. Cuiabá/MT. 2003.

GONZÁLEZ-RODRíGUEZ, M. et al. Bacteriological quality of aquacultured freshwater fish portions in prepackaged trays at 3 degrees C. J. Food Prot., v. 64, n. 9, p. 1399-1404, 2001.

HATHA, M. et al. Antibiotic resistance pattern of motile aeromonads from raised fresh water fish. Int. J. Food Microbiol., v. 98, n. 2, p. 131-134, 2005. nível de coliformes da amostra, maiores foram as contagens de Aeromonas spp., sendo as altas contagens e as baixas ou nulas, verificadas nos mesmos meses;

$\checkmark$ A contagem de bactérias heterotróficas aeróbias mesófilas, coliformes termotolerantes e Aeromonas spp. foi variável de acordo com o mês de coleta, tanto em peixes capturados no rio como nos cultivados, demonstrando o efeito da sazonalidade. As maiores quantidades de mesófilos, coliformes termotolerantes e Aeromonas spp. foram observadas no final do período seco e no período chuvoso, ou seja, nos meses mais quentes do ano (agosto a março).

KONEMAN. Diagnóstico microbiológico - texto e atlas colorido. Rio de Janeiro: Guanabara Koogan. 2008. 1565 p.

LIUSON, E. Pesquisa de coliformes totais, fecais e Salmonella spp. em tilápias de pesqueiros da região metropolitana de São Paulo. Dissertação apresentada ao curso de Pós-Graduação da UNESP. 2003. 94 p.

MENDES, P. P. et al. Análise estatística dos parâmetros aquícolas, com fins a otimização da produção. In: REUNIÃO ANUAL DA SOCIEDADE BRASILEIRA DE ZOOTECNIA, 43. Anais... 2006. João Pessoa, SBZ. Suplemento especial da Rev. Brasileira de Zootecnia, 2006. v. 35, p.886-903.

MÖLLERKE, R. D.; WIEST, J. M.; CARVALHO, H. H. C. Colimetrias como indicadores de qualidade de pescado artesanal do lago Guaíba, em Poto Alegre, RS. Hig. Aliment., v. 16, n. 99, p. 102, 2002.

MORALES, G. et al. Evaluación de la calidad bacteriológica de tilapia fresca (Oreochromis niloticus) proveniente de la Zona Norte de Costa Rica. ALAN, v. 54, n. 4, 2004.

MORES, V. L. Bactérias do gênero Aeromonas em peixe pintado (Pseudoplatystoma sp.) e pesquisa de alguns fatores de virulência a partir das cepas isoladas. São Paulo: USP. 1994. 122 p. Dissertação de Mestrado, Instituto de Ciências Biomédicas da Universidade de São Paulo.

PIAIA, I. I. Geografia de Mato Grosso. 2. ed. Cuiabá: EdUNIC, 1999. $207 p$.

PILARSKY, F. et al. Consórcio suíno-peixe: aspectos ambientais e qualidade do pescado. Rev. Bras. Zoot., v. 33, n. 2, p. 267-276, 2004. RANZANI-PAIVA, M. J. T.; TAKEMOTO, R. M. Sanidade de organismos aquáticos. São Paulo: Varela, 2004, 426 p.

SILIMON, K. Z. S. Piscicultura: a nova opção do produto rural matogrossense. Cuiabá, SEBRAE/MT, 1994. 100 p.

SILVA, N. et al. Manual de Métodos de Análise Microbiológica de Alimentos. São Paulo: Varela, 2001.

SILVA, M. C. D. et al. Avaliação da qualidade microbiológica de pescado comercializado em Maceió, AL. Hig. Aliment., v. 16, n. 96, p. 60-64, 2002.

SINGH, D. V.; SANYAL, S. C. Production of haemolysis and is correlation with enterotoxicity in Aeromonas spp. J. Med. Microbiol., v. 37, p. 262-267, 1992.

TESSARI, E. N. C. et al. Prevalência de Salmonella Enteritidis em carcaças de frango industriamente processadas. Hig. Alim., v. 17, n. 107, p. 52-55, 2003.

VIEIRA, R. H. S. S. et al. Influência das condições higiênico-sanitárias no processo de beneficiamento de tilápias (Oreochromis niloticus) em filés congelados. Hig. Alim., v. 14, n. 74, p. 37-40, 2000.

VIEIRA, R. H. S. S. Microbiologia, higiene e qualidade do pescado. Teoria e prática. São Paulo: Livraria Varela, 2004. 380 p.

ZAR, J. H. Biostatistical analysis. New Jersey:Prentice Hall, p. 531533, 1999. 